\title{
PERMAINAN “ABC 5 DASAR” UNTUK MENINGKATKAN PENGUASAAN KOSA KATA BAHASA ARAB
}

\author{
Khoirul Faizin \\ UIN Sunan Ampel Surabaya \\ Kfaizin6@gmail.com
}

\begin{abstract}
Media is one of the most important elements in learning. Because the influence of instructional media greatly affects the ability of students to capture material provided by the teacher. Good media is media that is in accordance with the conditions of students and not all media that use advanced technology rather than simple ones because the guidelines for making media are looking at the conditions of the environment and students. One of the most popular learning media for students is the game. The game invites students to learn by having fun, therefore, students will not feel objected and bored with the lesson because what they feel is playing and they unconsciously accept lessons from the game. One very communicative game is "ABC 5 Dasar". In this game students are invited to think and remember words in Arabic by making it part of the game. This study uses a development method and then the results of this research in the form of descriptive analysis that illustrates Arabic learning to improve Arabic vocabulary mastery or (mofradat) wrapped in traditional games in the form of the game "ABC 5 Dasar". It is hoped that this research can contribute to Arabic learning teachers to improve Arabic vocabulary mastery (mufradat).
\end{abstract}


Kata Kunci: Permainan ABC 5 Dasar, Mufradat

\section{Pendahuluan}

Berkembangnya suatu masa dipengaruhi oleh ilmu pengetahuan dan teknologi. Ilmu pengetahuan dan teknologi berjalan sejajar pada pondasi kemajuan suatu bangsa. Dalam perkembangan dan kemajuan ilmu pengetahuan sangat dipengaruhi oleh teknologi sebagai bagian dari komponen terciptanya pembelajaran yang efektif dan maksimal sehingga ilmu pengetahuan lebih mudah dan terjangkau untuk diterima sebagian besar masyarakat pada suatu bangsa.

Proses belajar dan mengajar tak lepas dari bahan ajar dan media pembelajaran. Media pembelajaran yang sesuai akan mampu membantu siswa dalam menangakap dan menerima pelajaran dengan tepat dan efisien. Bahan ajar yang baik adalah bahan ajar yang mampu memberikan pemahaman kepada siswa secara benar dan terukur sesuai kemampuan dan kondisi yang dihadapi siswa. Namun secara garis besar media bisa dipahami sebagai alat komunikasi yang digunakan untuk membawa informasi dari satu sumber kepada penerima. ${ }^{1}$ Oleh karena itu, bahan ajar yang sesuai dengan kondisi siswa sangatalah dibutuhkan agar tersampaikannya ilmu pengetahuan kepada siswa dengan sempurna. Media pembelajaran dibutuhkan oleh semua materi termasuk dalam pembelajaran Bahasa arab.

Dalam pembelajaran bahasa arab ada beberapa cabang keilmuan seperti berbicara bahasa arab, membaca tulisan arab, mendengar ucapanucapan orang arab, dan menulis tuisan berbahasa arab. Dari beberapa cabang keilmuan dalam belajar bahasa arab ada satu hal pokok yang harus dimiki oleh siswa yaitu penguasaan mufrodat. Karena mufrodat adalah hal mendasar yang harus dikuasai untuk memahami bahasa arab baik itu melalui mendengaran atau membaca.

Oleh karena itu, dalam hal ini peneliti ingin memodifikasi media pemebelajaran dengan menggunakan beberapa permainan tradisonal yang sering dimaikan oleh anak-anak desa untuk pembelajaran bahasa arab terkhusus untuk meningkatkan siswa dalam penguasaan mufrodat. Diharapkan siswa akan lebih mudah dan cepat dalam penguasaan mufrodat bahasa arab.

Metode penelitaian ini menggunakan metode penelitian pengembangan yaitu penelitian yang digunakan untuk menghasilkan 
produk dan menguji efektifitas produk tersebut. ${ }^{2}$ Penelitian ini mengembangkan media media pembelajaran berupa permainan tradisional dan kemudian diterapkan dalam pembelajaran bahasa arab kelas $\mathrm{V}$ madrasah ibtidaiyah untuk mempermudah siswa dalam penguasaan kosa kata bahasa arab (mufradat). Model pengembangan media pembelajaran dalam penelitian mengadopsi model 4D yang dikemukakan oleh Thiagarajan dkk.

Uji coba penelitian diterapkan media pembelajaran permainan "ABC 5 Dasar" sebanyak dua kali, subjek penelitian siswa kelas V madrasah ibtidaiyah islamiyah kedungbondo sebanyak 25 siswa, penelitian ini dilaksankan pada tahun ajaran 2019-2020 semester 1. Teknik pengumpulan data dengan menggunakan metode observasi dan angket. Sedangkan untuk mengetahui hasil belajar siswa peneliti melakukan tes berbentuk soal dengan pilihan ganda sebanyak 20 butir.

Uji validitas media pembelajaran menggunakan validitas ahli. Instrumen lembar validasi media menggunakan skala likert dengan kriteria (1) sangat tidak baik, (2) tidak baik, (3) baik, dan (4) sangat baik. Teknik analisis data uji validitas rumus dari Ridwan dan Sunarto ${ }^{3}$ yaitu :

$$
\chi=\frac{\sum \chi_{1}+\Sigma \chi_{2}}{n}
$$

Keterangan:

$\mathrm{X}=$ Kriteria penlilaian media pembelajaran permainan "ABC 5 Dasar"

$\begin{array}{ll}\sum \mathrm{X} 1 & =\text { Total skor penilaian validator } 1 \\ \sum_{\mathrm{n}} \mathrm{X} 2 & =\text { Total skor validator } 2 \\ & =\text { Jumlah validator }\end{array}$

Sedangkan uji reabilitas media pembelajaran menggunakan uji reliabilitas teknik ulang yaitu uji reliabilitas teknik ulang instrumen diujicobakan kepada sekelompok responden dan hasilnya dicatat ${ }^{4}$. Uji coba media pembelajaran dilakukan dua kali. Uji coba pertama dilaksanakan untuk mengetahui reliabilitas media pembelajaran permainan "ABC 5 Dasar" di ujicobakan kepada 10 siswa, perwakilan dari 3 siswa yang memiliki kemampuan baik, 3 siswa memiliki kemampuan sedang dan 4 siswa memiliki kemampuan lambat. Teknik analisis data untuk menghitung reliabilitas adalah :

\footnotetext{
${ }^{2}$ Sugiyono, Metode Penelitian Pendidikan : Pendekatan Kuantitatif, Kualitatif dan $\mathrm{R} \& \mathrm{D}$, (Bandunug : Alfabeta, 2012) 407

${ }^{3}$ Ridwan, Sunarto, Pengantar Statistika: Untuk Penelitian Pendidikan, Sosial, Ekonomi, Komunikasi, dan Bisnis, (Bandung: Alfabeta, 2009)38

${ }^{4}$ Arikunto, Prosedur Penelitian: Suatu Pendekatan Praktik, (Jakarta: Rineka Cipta, 2010) 222
} 


$$
\chi=\frac{\sum \chi_{1}+\sum \chi_{2}+\sum \chi_{3}}{n}
$$

Keterangan :

$\mathrm{X}=$ Total skor tanggapan siswa terhadap media permainan "ABC 5 Dasar"

$\begin{array}{ll}\sum \mathrm{X} 1 & =\text { Total skor siswa kemampuan baik } \\ \sum \mathrm{X} 2 & =\text { Total skor siswa kemampuan sedang } \\ \sum_{\mathrm{n}} \mathrm{X} 3 & =\text { Total skor siswa kemampuan lambat } \\ & =\text { Jumlah siswa }\end{array}$

Uji validitas instrumen motivasi belajar menggunakan uji konstruk. Untuk menganalisis hasil pengamatan aktifias siswa menggunakan analisis presentase (\%), yakni banyaknya frekuensi tiap aktifitas dibagi seluruh aktifitas kemudian dikalikan 100\%. Hasil penelitan ini berupa deskriptif analisis yang menggambarkan tentang pembelajaran bahasa arab untuk peningkatan penguasaan kosa kata bahasa arab atau (mofradat) yang di bungkus dengan permainan tradisional berupa permainan "ABC 5 Dasar". Diharapkan penelitian ini dapat memberikan sumbangsih kepada guru pembelajaran bahasa arab untu meningkatkan penguasaan kosa kata bahasa arab (mufradat).

\section{Pengertian Media Pembelajaran}

Kata "media" berasal dari bahasa latin yang merupakan jamak dari kata "medium", istialah ini merujuk pada apa saja yang membawa informasi antara sebuah sumber dan penerima ${ }^{5}$. media adalah segala bentuk alat komunikasi yang dapat digunakan untuk menyampaikan informasi dari sumber ke peserta didik. Banyak ahli yang memberikan batasan tentang media pembelajaran. AECT (Association of Educational and Communication Technology, 1977) memberikan batasan media pembelajaran adalah segala sesuatu yang digunakan orang untuk menyalurkan pesan dan informasi ${ }^{6}$. Media juga memiliki pengertian sebagai segala sesuatu yang dapat digunakan untuk menyalurkan pesan yang dapat merangsang pikiran, perasaan, perhatian, dan kemauan siswa untuk belajar ${ }^{7}$. Dari beberapa paparan diatas peniliti mengambil kesimpulan bahwa media pembelajran adalah alat yang digunakan guru untuk mempermudah dalam menyampaikan suatu pesan terkait ilmuan

\footnotetext{
${ }^{5}$ Sharon E. Smaldino, Deborah L. Lowther, James D. Tussell. Intructional Technology \& Media for learning. Terjemah: Arif Rahman. (Jakarta : Perdana Media Group, 2011) 7

${ }^{6}$ Arsyad. A, Media Pembelajaran, (Jakarta: Raja Wali Pers, 2013) 3

${ }^{7}$ Togala, Zulrahmat, Media Pembelajaran, Konsep dan Pemanfaatan. 4.
} 
kepada siswa. Keefektifitasan suatu media pembelajaran adalah berpatokan kepada siswa dimana kondisi siswa adalah ukuran untuk membuat bahan agar sesuai dengan kebutuhan dan kemampuan siswa.

Media pembelajaran pada umumnya terdiri dari dua komponen penting yaitu unsur peralatan atau perangkat dan unsur pesan yang dibawa oleh media tersebut. Satu contoh papan tulis adalah jenis media pembelajaran diamana wujud papan tulis tersebut memang terlihat dan jelas namun tidak akan bisa menyampaikan apapun kalau tidak diberi nilai-nilai pesan pada papan tulis tersebut seperti di beri tulisan " كتب = menulis" kemudian murid disuruh membaca maka media tersebut akan bisa menyampaian informasi bahwa "كتب" memiliki arti "menulis". Dalam kegiatan belajar mengajar, sering pula pemakaian media pembelajaran atau (الوسائل التعليمية) digantikan dengan istilah-istilah seperti alat pandang dengar, bahan pengajaran (intructional materi), komunikasi pandang dengar (audio-visual communication), pendidikan alat peraga pandang (visual education), teknologi pendidikan (educational technology), alat peraga (وسائل الايضاح) dan media penjelas الوسائل) 8 (التوضيحية)

\section{Manfaat dan Fungsi media pembelajaran}

Penggunaan media dalam pembelajaran tentunya memiliki tujuan dan manfaat. Secara umum media harus mampu memberikan kesan yang lebih baik dan memberikan pemahaman yang lebih mendalam kepada siswa dari pada tanpa ada media pembelajaran. Karena dalam pengertiannya media adalah alat yang digunakan untuk menyampaikan pesan kepada siswa. Manfaat yang dapat dirasakan dalam penggunaan media pembelajaran antara lain adalah: a) memperjelas penyajian pesan dan informasi; b) meningkatkan dan mengarahkan perhatian; c) dapat mengatasi keterbatasan indera, ruang dan waktu; d) memberikan kesamaan pengalaman kepada siswa tentang peristiwa-peristiwa di lingkungan mereka9. Selain itu media juga memiliki fungsi dalam sebuah pembelajaran terutama pembelajaran bahasa arab sebagai bahasa asing bagi siswa, maka butuh bahan ajar yang benar-benar sesuai dan layak di gunakan siswa antara. Fungsi umum media pembelajaran adalah sebagai pembawa pesan dari guru ke murid dalam rangka mencapai tujuan pembelajaran. Fungsi khusus media pembelajaran adalah sebagai berikut:

\footnotetext{
8 Arsyad. A, (2013) 6

9. Arsyad, A. Bahasa arab dan Metode Pengajarannya, (Yogyakarta: Pustaka Pelajar, 2004) 6
} 
1. untuk menarik perhatian murid

2. untuk memperjelas penyampaian pesan

3. untuk mengatasi keterbatasan ruang, waktu, dan biaya

4. untuk menghindari adanya verbalisme dan salah tafsir

5. untuk mengaktifkan dan mengefektifkan kegiatan belajar murid ${ }^{10}$

\section{Pembelajaran Bahasa Arab}

Pembelajaran adalah proses, cara, perbuatan menjadikan orang atau makhluk hidup belajar ${ }^{11}$. dengan kata lain pembelajaran adalah suatu kegiatan yang menuntut menusia untuk berpikir untuk mendapatkan pengetahuan baru dengan belajar. proses pembelajaran juga bisa diartikan sebagai suatu rangkaian interaksi antara siswa dan guru dalam rangka mencapai tujuan ${ }^{12}$. Dalam pembelajaran ada fasilitas dan perlengkapan terdiri dari ruang kelas dan audio visual, prosedur meliputi jadwal dan metode penyampaian informasi, praktek belajar, ujian dan sebagainya ${ }^{13}$.

Dalam Pembelajaran ada dua istilah yang saling terikat yaitu belajar dan mengajar. Belajara adalah suatu proses yang diatandai oleh adanya perubahan pada diri seseorang. Perubahan itu dapat berupa perubahan pengetahuannya, pemahamannya, sikap dan tingkahlakunya, kecakapan keterampilannya, daya kreasinya, daya penerimaannya, dan lain-lain aspek yang ada pada individu. Sementara itu "mengajar" adalah fasilitas proses belajar yang membutuhkan perubahan atau peningkatan tersebut. Mengajar yaitu proses mengatur mengorganisasikan lingkungan yang ada disekitar siswa sehingga dapat menimbulkan atau mendorong siswa melakukan proses belajarnya ${ }^{14}$.

Bahasa adalah bunyi yang keluar dari seseorang dan memiliki makna yang dipahami oleh masyarakat di suatu tempat yang digunakan untuk berkomunikasi diantara mereka. Sedangkan menurut Muhammad al-Mubarak bahasa adalah alat yang unik yang dapat memindahkan sesuatu yang diterima oleh panca indera kepada hat ${ }^{15}$. Bisa disimpulkan bahwa bahasa adalah suatu pekerjaan untuk mengungkapkan sesuatu dengan ucapan dan memberikan pengertian kepada orang lain tentang apa yang ingin diketahui.

\footnotetext{
${ }^{10}$ Kustiawan, Usep, Pengembangan Media Pembelajaran Anak Usia Dini. (Gunung Samudera, 2016) 6.

${ }^{11}$ Kamus Besar Bahasa Indonesia

12 Abin Syamsuddin Makmun, Psikologi Pendidikan, ( Bandung: PT. Remaja Rosda Karya, 2005) 156

${ }^{13}$ Oemar Hamalik, Kurikulum dan Pembelajaran, (Jakarta: Bumi Aksara, 1995) 57

${ }^{14}$ Nana Sudjana, Media Pengajaran, (Bandung: Sinar Baru, 1997) 15-16

15 Abdul Mu'in, Analisis Kontrastif Bahasa Arab dan Bahasa Indonesia (Telaah terhadap Fonetik dan Morfologi), (Jakarta: Pustaka AlHusna Bar, 2004) 37
} 
Sedangkan bahasa arab adalah bahasa yang digunakan orang-orang arab untuk berkomuniasi dengan sesamanya. Dalam bahasa arab ada dua jenis bahasa arab yaitu fusha dan amiyah. Fusha adalah bahasa resmi layaknya bahasa indonesia sedangkan bahasa amiyah adalah bahasa yang dipakai oleh masyarakat di pedesaan dan pasaran seperi bahasa daerah di Indonesia.

\section{Mufrodat}

Mufrodat adalah istilah kosa kata dalam bahasa arab yang berisi persamaan arti kata antara bahasa arab dan bahasa Indonesia. Mufrodat sangat dibutuhkan dan sangat penting bagi pembelajara bahasa asing karena mufrodat adalah bahan untuk meracik kata sehingga menjadi susunan suatu kalimat yang dapat dimengerti dan dipelajari.

Kosakata merupakan kumpulan kata-kata tertentu yang akan membentuk bahasa. Kata adalah bagian terkecil dari bahasa yang sifatnya bebas. Pengertian ini membedakan antara kata dengan morfem. Morfem adalah satuan bahasa terkecil yang tidak bisa dibagi atas bagian bermakna yang lebih kecil yang maknanya relative stabil ${ }^{16}$. Dalam pembelajaran kosa kata ada beberapa hal yang harus diperhatikan, antara lain adalah sebagai berikut ${ }^{17}$.

1. Pembelajaran kosakata (al-mufradât) tidak berdiri sendiri. Kosakata (al-mufradât) hendaknya tidak diajarkan sebagai mata pelajaran yang berdiri sendiri melainkan sangat terkait dengan pembelajaran muthâla'ah, istimâ', insyâ', dan muhâdatsah.

Pembatasan makna. Dalam pembelajaran kosakata hendaknya makna harus dibatasi sesuai dengan konteks kalimat saja, mengingat satu kata dapat memiliki beberapa makna. Bagi para pemula, sebaiknya diajarkan kepada makna yang sesuai dengan konteks agar tidak memecah perhatian dan ingatan peserta didik. Sedang untuk tingkat lanjut, penjelasan makna bias dikembangkan dengan berbekal wawasan dan cakrawala berpikir yang lebih luas tentang makna kata dimaksud.

2. Kosakata dalam konteks. Beberapa kosakata dalam bahasa asing (Arab) tidak bisa dipahami tanpa pengetahuan tentang cara pemakaiannya dalam kalimat. Kosakata seperti ini hendaknya diajarkan dalam konteks agar tidak mengaburkan pemahaman siswa.

3. Terjemah dalam pengajaran kosakata. Pembelajaran kosakata dengan cara menerjemahkan kata ke dalam bahasa ibu adalah cara yang

${ }_{16}$ Harimurti Kridalaksana, Kamus Linguistik, Jakarta: PT.Gramedia Pustaka Utama, 1983) 157

${ }^{17}$ A. Fuad Effendy, Metodologi Pengajaran Bahasa Arab (Malang: Misykat, 2005), 97-98 
paling mudah, namun mengandung beberapa kelemahan. Kelemahan tersebut antara lain dapat mengurangi spontanitas siswa ketika menggunakannya dalam ungkapan saat berhadapan dengan benda atau objek kata, lemah daya lekatnya dalam ingatan siswa, dan juga tidak semua kosakata bahasa asing ada padanannya yang tepat dalam bahasa ibu. Oleh karena itu, cara penerjemahan ini direkomendasikan sebagai senjata terakhir dalam pembelajaran kosakata, digunakan untuk kata-kata abstrak atau kata-kata yang sulit diperagakan untuk mengetahui maknanya.

4. Tingkat kesukaran. Bila ditinjau dari tingkat kesukarannya, kosakata bahasa Arab bagi pelajara di Indonesia dapat dibedakan menjadi tiga, antara lain:

a. Kata-kata yang mudah, karena ada persamaannya dengan katakata dalam bahasa Indonesia, seperti : رحمة ، كرسي ، كتاب ، علماء

b. Kata-kata yang sedang dan tidak sukar meskipun tidak ada مدينة، سوق، : persamaannya dalam bahasa Indonesia, seperti مهب

c. Kata-kata yang sukar, baik karena bentuknya maupun pengucapannya, misalnya : انزلق ، تدهور ، استولى

\section{Permainan ABC 5 Dasar}

Permainan ABC 5 dasar bisa dimainkan minimal dua orang. Berbeda dengan permainan lain yang mayoritas mengandalkan kelincahan atau keterampilan, permainan ini lebih membutuhkan pengetahuan dan kecerdasan. Untuk memainkan ini, barang yang dibutuhkan hanya kertas dan pulpen atau pensil.

Semua pemain menyumbangkan jarinya untuk menentukan huruf apa yang akan digunakan sebagai patokan. Sebagai contoh, ada 7 jari, maka dihitung dari abjad pertama, jatuh pada huruf ketujuh, yaitu G. Setelah itu semua harus segera menuliskan segala sesuatu yang diawali dengan huruf $\mathrm{G}$ dalam waktu tertentu.

Setelah waktu berakhir, jawaban peserta dicocokkan dan dinilai. Jawaban yang sama dengan pemain lainnya mendapat nilai 50 , sedangkan jawaban yang berbeda dengan pemain lainnya mendapat nilai 100. Skor terbanyak dari permainan ini akan keluar sebagai pemenang.

Lebih simpelnya ada beberapa tahapan dalam permainan ABC 5 Dasar anara lain: 
1. ABC 5 dasar adalah salah satu permainan yang membutuhkan kecerdasan. Biasa dimainkan dua orang atau lebih. Alat yang dibutuhkan yakni kertas dan bolpen atau pensil. Semua orang akan menyumbangkan jari di awal permainan untuk menentukan huruf apa yang akan dijadikan sebagai patokan.

2. Misalnya setelah dihitung dan diurutkan alfabetnya jatuh di huruf C. Maka semua harus siap untuk menuliskan segala sesuatu yang berawalan dengan huruf $\mathrm{C}$ di dalam tabel yang sudah dibuat di awal permainan. Tidak boleh mencontek, jika waktu pencocokan ditemukan kesamaan maka akan mendapat skor 50. Jika tidak ada kesamaan dengan pemain lain maka skor yang didapat adalah 100.

3. Adapaun tabel - tabel yang dimaksudkan untuk diisi diantaranya berisi: nama orang, nama buah, nama hewan, nama negara, nama produk atau iklan, dan lain - lainnya. Untuk kolom yang tidak diisi maka skornya 0 . Di akhir permainan semua skor akan ditotal. Orang dengan skor terbanyak akan dijadikan sebagai pemenang ${ }^{18}$.

\section{Hasil Penelitian}

Berikut adalah uraian secara rinci hasil pengembangan dan implementasi media pembelajaran permainan "ABC 5 Dasar".

\section{Validitas Konstruk}

Validasi media pembelajaran permainan "ABC 5 Dasar" dilakukan oleh 2 ahli yang terdiri dari ahli pendidikan yang bernama Moh. Muhajir, M.Pd.I juga sebagai Dosen di STAI Attanwir dan ahli bidang psikologi anak bernama Indah Fajrotuz Zahro, M.Psi. yang juga aktif dalam komunitas pelestarian permainan tradisional di kabupaten Bojonegoro. Berikut adalah hasil validasi dari ahli.

\begin{tabular}{|c|l|l|l|}
\hline \multirow{2}{*}{ No } & \multicolumn{2}{|c|}{ Aspek Penilaian } & \multicolumn{2}{c|}{ Skor } \\
\cline { 3 - 4 } & \multicolumn{1}{|c|}{ Validator1 } & Validator 2 \\
\hline 1 & Penampilan media pembelajaran & Baik & Sangat Baik \\
\hline 2 & $\begin{array}{l}\text { Kesesuaian media pembelajaran } \\
\text { dengan tujuan pembelajaran }\end{array}$ & Sangat Baik & Baik \\
\hline 3 & $\begin{array}{l}\text { Kesesuaian media pembelajaran } \\
\text { dengan kriteria siswa }\end{array}$ & Baik & Bai \\
\hline 4 & $\begin{array}{l}\text { Kesesuaian media dengan konsep } \\
\text { pembelajaran }\end{array}$ & Sangat Baik & Sangat Baik \\
\hline 5 & Kesesuaian media dengan isi & Sangat Baik & Sangat Baik \\
\hline
\end{tabular}

18. Di akses di https://thegorbalsla.com/permainan-tradisional/ pada Rabu 19 feb 2020 


\begin{tabular}{|c|l|l|l|}
\hline & konten pembelajran & & \\
\hline 7 & $\begin{array}{l}\text { Petunjuk penggunaan media } \\
\text { pembelajaran }\end{array}$ & Sangat Baik & Sangat Baik \\
\hline
\end{tabular}

Keterangan :

Skor 0-1 sangat tidak baik (media tidak dapat digunakan)

Skor 1-2 tidak baik (media memerlukan konsultasi dan revisi)

Skor 2-3 baik (media dapat digunakan dan memerlukan sedikit revisi)

Sor 3-4 sangat baik (media dapat digunakan)

Pengembangan media pembelajaran tersebut menggunakan prinsip evaluasi yang dikemukakan oleh Asnawir dan Usman yaitu: (1) media pembelajaran harus sesuai dengan materi pembelajaran yang diterapkan, (2) media tersebut harus bisa dilihat dan didengar, (3) media pengajaran harus dapat merespon siswa belajar, dan (4) media pengajaran harus sesuai dengan kondisi individu siswa ${ }^{19}$. Berdasarkan hasil penilaian 2 ahli sebagai validator tersebut maka media pembelajaran ini valid dan layak untuk digunakan dalam pembelajaran.

\section{Reliabilitas Teknik Ulang}

Uji reliabilitas eksternal teknik ulang dilakukan mengujicobakan instrumen atau produk yang dikembangkan beberapa kali dan kemudian hasilnya dicatat ${ }^{20}$. Uji coba diterapkan pada 10 siswa, 3 siswa berkemampuan baik, 3 siswa berkemampuan sedang dan 4 siswa berkemampuan lemah. Uji reliabilitas dilakukan dengan memberikan angket pada siswa terhadap penggunaan media pembelajaran permainan "ABC 5 Dasar". Berikut adalah hasl uji reliabilitas:

\begin{tabular}{|c|l|c|c|}
\hline \multirow{2}{*}{ No } & \multicolumn{1}{|c|}{ Keterangan } & \multicolumn{2}{c|}{ Kriteria jawaban siswa } \\
\cline { 2 - 4 } & $\begin{array}{l}\text { Apakah permainan ABC 5 Dasar } \\
\text { menarik }\end{array}$ & 10 & $100 \%$ \\
\hline 2 & $\begin{array}{l}\text { Apakah media permainan ABC 5 } \\
\text { Dasar mudah digunakan }\end{array}$ & 10 & $100 \%$ \\
\hline 3 & $\begin{array}{l}\text { Apakah kamu mengerti isi yang } \\
\text { disampaikan guru }\end{array}$ & 10 & $100 \%$ \\
\hline 4 & $\begin{array}{l}\text { Apakah kamu suka dengan } \\
\text { permaianan ABC 5 Dasar }\end{array}$ & 10 & $100 \%$ \\
\hline
\end{tabular}

19. Asnawir, M.Usman, Basyiruddin, Media Pembelajaran, (Jakarta : Ciputat Pres, 2002)19 20 . Arikunto, Prosedur Penelitian: Suatu Pendekatan Praktik, 222 
Sumber : Data sudah di olah

Berdasarkan paparan data diatas diketahui bahwa pembelajaran bahasa arab untuk peningkatan penguasaan kosa kata bahasa arab (mufradat) menggunakan media permainan ini sangat layak untuk digunakan siswa meskipun dengan karakterisik kemampuan yang berbeda. Dalam uji coba penerapan media ini tidak ada kendala atau hambatan dan hal tersebut menunjukan keajegan pada media pembelajaran ini.

Berikut adalah beberapa penjelasan yang telah peneliti paparkan, ada beberapa tahapan penting dalam permainan tersebut. Antara lain;

1. Alat yang dibutuhkan yakni kartu mufradat dan bolpen atau pensil. Semua orang akan menyumbangkan jari di awal permainan untuk menentukan huruf apa yang akan dijadikan sebagai patokan.

2. Sebuah contoh setelah dihitung dan diurutkan huruf hijaiyah jatuh di huruf " $\varepsilon$ ". Maka semua harus siap untuk menuliskan segala sesuatu yang berawalan dengan huruf " $\varepsilon$ " di dalam tabel yang sudah dibuat di awal permainan. Tidak boleh mencontek, jika waktu pencocokan ditemukan kesamaan maka akan mendapat skor 50. Jika tidak ada kesamaan dengan pemain lain maka skor yang didapat adalah 100 . Untuk kolom yang tidak diisi maka skornya 0 .

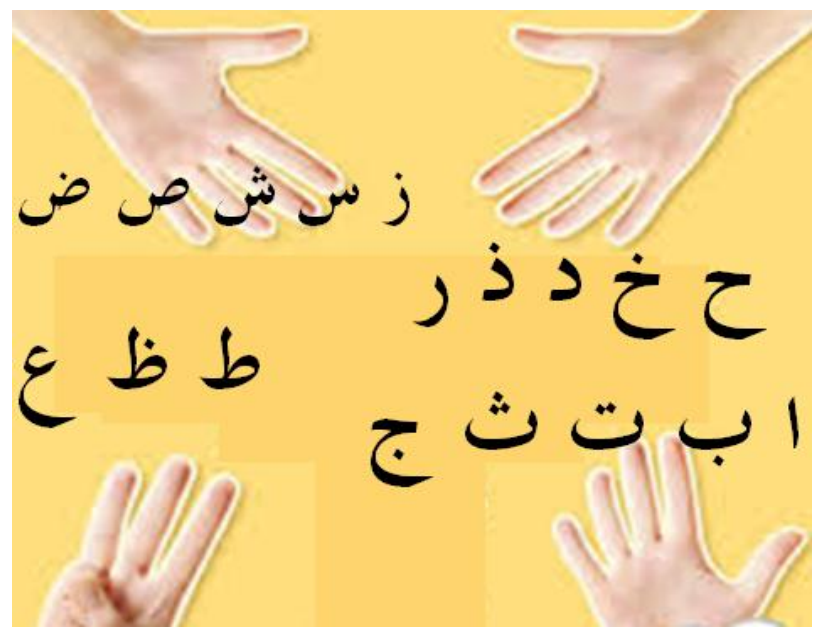

3. Adapaun kartu mufradat berisi: isim dan fi'il Di akhir permainan satu persatu siswa membacakan kata yang sudah ia tulis 


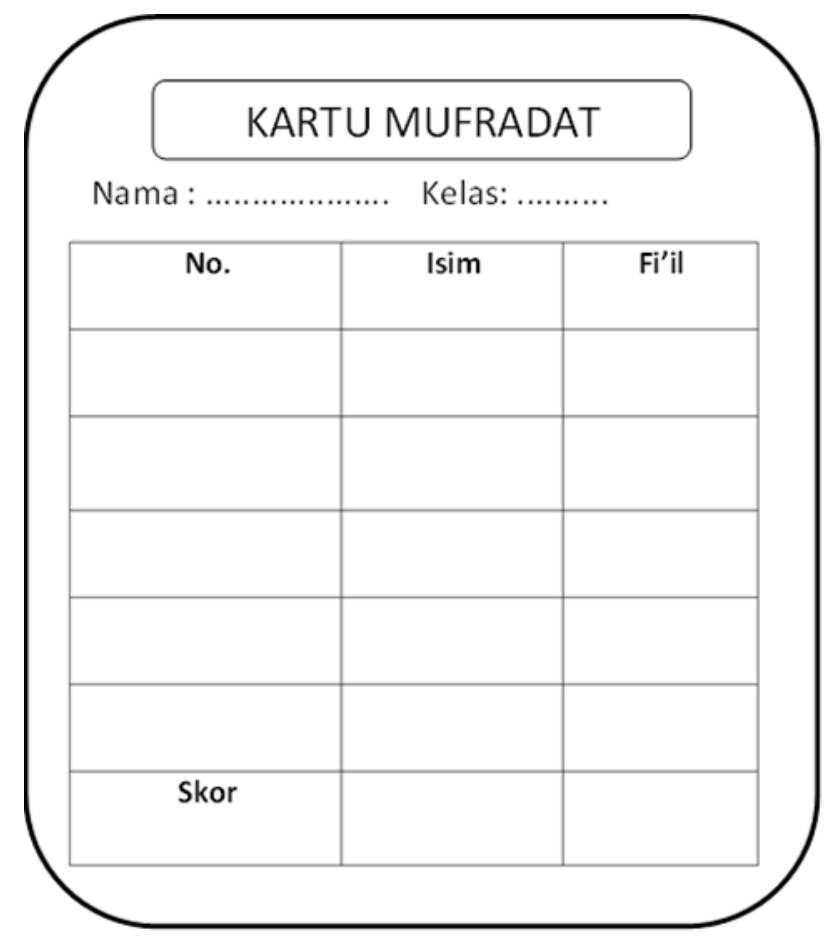

4. Setelah semua kata yang ditulis selesai dibaca, maka tugas siswa adalah mengucapkan ulang kata temannya yang lain. Setiap kata yang bisa diulang maka akan mendapatkan nilai tambahan 50. Jadi semakin banyak menyebutkan kosa kata maka semakin banyak poinnya.

5. Diakhir permainan poin yang dikumpulkan dijumlah menjadi semua. Nilai tertinggi adalah pemenang dalam permainan ini.

Desain pengembangan penelitian ini mengacu kepada desain 4D pengembangan Thiagarajan, dkk. Dimana pengembangan media pembelajaran permainan "ABC 5 Dasar" melakukan tahapan define, design, develop, dan dissaminate. Alur tersebut mencakup analisis karakteristik siswa, analisis tujuan pembelajaran, analisis isi konten materi pembelajaran, analisis kebutuhan siswa, uji coba media pembelajaran, dan pelaporan.

\section{Hasil Belajar}

Setelah menggunakan media bahan ajar permainan "ABC 5 Dasar" hasil nilai siswa menunjukan ada kenaikan 40\% lebih tinggi setelah menggunakan media ini dari pada tidak media sebelumnya. Siswa yang memiliki nilai diatas KKM ( Kriteria Ketuntasan Minimum) yaitu dari 
yang sebelum menggunakan media ada nilai $60 \%$ siswa yang berda diatas KKM namun setelah menggunakan media "ABC 5 Dasar" ini naik menjadi tuntas 100\% diatas KKM. Berikut adalah tabel penialaian hasil belajar siswa sebelum dan sesudah menggunakan media pembelajaran permainan "ABC 5 Dasar".

\begin{tabular}{|l|l|l|}
\hline \multirow{2}{*}{ Keterangan } & \multicolumn{1}{|c|}{ Sebelum } & Sesudah \\
\cline { 2 - 3 } & Nilai $<$ KKM & Nilai $<$ KKM \\
\hline Hasil Belajar & $\mathbf{6 0} \%$ & $\mathbf{1 0 0} \%$ \\
\hline
\end{tabular}

\section{Penutup}

Dalam penelitian ini dapat diketahui bahwa media pembelajaran permainan "ABC 5 Dasar" sangat efektif dan aplikatif untuk meningkatan siswa dalam penguasaan kosa kata bahasa arab "mufradat" dengan kenaikan nilai diatas KKM dengan presentase 40\% setelah dan sebelum digunakannya media pembelajaran ini. beberapa hal penting dalam penelitian ini antara lain: (1) Dalam pembelajar bahasa arab mufradat akan selalu dibutuhkan oleh karena itu menjadi sangat wajib bagi siswa untuk menghafal mufradat, (2) Mengahafal adalah proses yang paling berat oleh karena itu butuh strategi khusus agar siswa tidak terbebani dengan mufrodat dan materi bisa dikuasai dengan maksimal oleh siswa, (3) Media pembelajaran yang tepat adalah salah satu komponen terpenting dalam tercapainya pembelajaran yang baik dan optimal. Oleh karena itu dalam permasalahan kali ini peneliti mencari beberapa solusi penyelesaian dengan menggabungkan beberapa permainan tradisional yang dalam hal ini adalah permainan "ABC 5 Dasar" dengan memasukan nilai-nilai pembelajaran mufrodat dalam permainan tersebut, (5) Permainan "ABC 5 Dasar" memiliki beberapa keunikan karena didalamnya ada unsur-unsur berpikir dan mengingat. Unsur yang sama dalam pembelajaran mufrodat yaitu berpikir dan mengingat. Oleh karena itu permainan ini sangat sinkron jika dikembangkan menjadi media dalam pembelajaran bahasa arab dalam penguasaan kosa kata bahasa arab (mufradat). 


\section{Daftar Pustaka}

Abin Syamsuddin Makmun, Psikologi Pendidikan. Bandung: PT. Remaja Rosda Karya, 2005.

Abdul Mu'in, Analisis Kontrastif Bahasa Arab dan Bahasa Indonesia Telaah terhadap Fonetik dan Morfologi). Jakarta: Pustaka AlHusna Bar, 2004.

A. Fuad Effendy, Metodologi Pengajaran Bahasa Arab. Malang: Misykat, 2005.

Arsyad, A. Bahasa arab dan Metode Pengajarannya. Yogyakarta: Pustaka Pelajar, 2004.

Arikunto, Prosedur Penelitian: Suatu Pendekatan Praktik, Jakarta: Rineka Cipta, 2010.

Arsyad. A, Media Pembelajaran. Jakarta: Raja Wali Pers, 2013.

Asnawir, M.Usman, Basyiruddin, Media Pembelajaran, Jakarta : Ciputat Pres, 2002.

Harimurti Kridalaksana, Kamus Linguistik. Jakarta: PT.Gramedia Pustaka Utama, 1983.

Kamus Besar Bahasa Indonesia.

Ridwan, Sunarto, Pengantar Statistika: Untuk Penelitian Pendidikan, Sosial, Ekonomi, Komunikasi, dan Bisnis, Bandung: Alfabeta 2009.

Kustiawan, Usep, Pengembangan Media Pembelajaran Anak Usia Dini. Gunung Samudera, 2016.

Nana Sudjana, Media Pengajaran. Bandung: Sinar Baru, 1997.

Oemar Hamalik, Kurikulum dan Pembelajaran. Jakarta: Bumi Aksara, 1995.

Sundayana, Rustina, Media Pembelajaran Matematika. Bandung : Alfabeta,2013.

Sugiyono, Metode Penelitian Pendidikan : Pendekatan Kuantitatif, Kualitatif dan R \& D, Bandunug: Alfabeta, 2012.

Sharon E. Smaldino, Deborah L. Lowther, James D. Tussell. Intructional Technology \& Media for learning. Terjemah: Arif Rahman. Jakarta : Perdana Media Group, 2011.

Togala, Zulrahmat, Media Pembelajaran, Konsep dan Pemanfaatan

Di akses di https://thegorbalsla.com/permainan-tradisional/ pada Rabu 19 feb 2020. 